\title{
Updated USPSTF screening guidelines may reduce lung cancer deaths
}

\section{By nearly doubling the number of patients eligible for screening, as many as 60,000 US lives may be saved-but concerns may limit acceptance.}

\section{PRACTICE CHANGER}

Start assessing risk and screening for lung cancer at age 50 in patients who have a 20-pack-year history of smoking, using low-dose computed tomography (LDCT) scanning. This practice, based on a 2020 US Preventive Services Task Force (USPSTF) guideline update, is expected to reduce annual mortality from lung cancer by an additional $3 \%$ or more (from $9.8 \%$ to $13 \%$ ).

STRENGTH OF RECOMMENDATION

A: Evidence-based clinical practice guideline ${ }^{1}$

US Preventive Services Task Force. Lung cancer: screening. Final recommendation statement. March 9, 2021. Accessed August 19, 2021. https://uspreventiveservicestaskforce.org/uspstf/recommendation /lung-cancer-screening

\section{ILLUSTRATIVE CASE}

A 50-year-old woman presents to your office for a well-woman exam. Her past medical history includes a 22-pack-year smoking history (she quit 5 years ago), well-controlled hypertension, and mild obesity. She has no family history of cancer, but she does have a family history of type 2 diabetes and heart disease. Besides age- and risk-appropriate laboratory tests, cervical cancer screening, breast cancer screening, and initial colon cancer screening, are there any other preventive services you would offer her?
$\mathrm{L}$ ung cancer is the second most common cancer in both men and women, and it is the leading cause of cancer death in the United States-regardless of gender. The American Cancer Society estimates that 235,760 people will be diagnosed with lung cancer and 131,880 people will die of the disease in $2021 .^{2}$

In the 2015 National Cancer Institute report on the economic costs of cancer, direct and indirect costs of lung cancer totaled $\$ 21.1$ billion annually. Lost productivity from lung cancer added another $\$ 36.1$ billion in annual costs. ${ }^{3}$ The economic costs increased to $\$ 23.8$ billion in 2020 , with no data on lost productivity. ${ }^{4}$

Smoking tobacco is by far the primary risk factor for lung cancer, and it is estimated to account for $90 \%$ of all lung cancer cases. Compared with nonsmokers, the relative risk of lung cancer is approximately 20 times higher for smokers. ${ }^{5,6}$

Because the median age of lung cancer diagnosis is 70 years, increasing age is also considered a risk factor for lung cancer. ${ }^{2,7}$

Although lung cancer has a relatively poor prognosis-with an average 5-year survival rate of $20.5 \%$ - early-stage lung cancer is more amenable to treatment and has a better prognosis (as is true with many cancers). ${ }^{1}$

LDCT has a high sensitivity, as well as a reasonable specificity, for lung cancer detection. There is demonstrated benefit
Robert C. Marshall, MD, MPH, MISM, FAAFP, FAMIA; Samuel Miguel Tiglao, DO, FAAFP; Derrick Thiel, MD Madigan Family Medicine Residency, Joint Base Lewis-McChord, WA

DEPUTY EDITOR Corey Lyon, DO University of Colorado, Family Medicine Residency, Denver

doi: $10.12788 /$ jp. 0257 


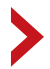

This updated guideline nearly doubles eligibility for lung cancer screening using low-dose CT scanning. in screening patients who are at high risk for lung cancer. ${ }^{8-11}$ In 2013, the USPSTF recommended annual lung cancer screening (B recommendation) with LDCT in adults 55 to 80 years of age who have a 30-pack-year smoking history, and who currently smoke or quit within the past 15 years. ${ }^{1}$

\section{STUDY SUMMARY}

\section{Broader eligibility for screening supports mortality benefit}

This is an update to the 2013 clinical practice guideline on lung cancer screening. The USPSTF used 2 methods to provide the best possible evidence for the recommendations. The first method was a systematic review of the accuracy of screening for lung cancer with LDCT, evaluating both the benefits and harms of lung cancer screening. The systematic review examined various subgroups, the number and/or frequency of LDCT scans, and various approaches to reducing false-positive results. In addition to the systematic review, they used collaborative modeling studies to determine the optimal age for beginning and ending screening, the optimal screening interval, and the relative benefits and harms of various screening strategies. These modeling studies complemented the evidence review.

The review included 7 randomized controlled trials (RCTs), plus the modeling studies. Only the National Lung Screening Trial (NLST; $N=53,454$ ) and the NederlandsLeuvens Longkanker Screenings Onderzoek (NELSON) trial $(\mathrm{N}=15,792)$ had adequate power to detect a mortality benefit from screening (NLST: relative risk reduction $=16 \%$; $95 \% \mathrm{CI}, 5 \%-25 \%$; NELSON: incidence rate ratio $=0.75 ; 95 \% \mathrm{CI}, 0.61-0.90)$ compared with no screening.

Screening intervals, from the NLST and NELSON trials as well as the modeling studies, revealed the greatest benefit from annual screening (statistics not shared). Evidence also showed that screening those with lighter smoking histories (<30 pack-years) and at an earlier age (age 50) provided increased mortality benefit. No evidence was found for a benefit of screening past 80 years of age. The modeling studies concluded that the 2013 USPSTF screening program, using a starting age of 55 and a 30-pack-year smoking history, would reduce mortality by $9.8 \%$, but by changing to a starting age of 50 , a 20 -packyear smoking history, and annual screening, the mortality benefit was increased to $13 \%$. $^{1,11}$

Comparison with computer-based risk prediction models from the Cancer Intervention and Surveillance Modeling Network (CISNET) revealed insufficient evidence at this time to show that prediction modelbased screening offered any benefit beyond that of the age and smoking history risk factor model.

The incidence of false-positive results was $>25 \%$ in the NLST at baseline and at 1 year. Use of a classification system such as the Lung Imaging Reporting and Data System (Lung-RADS) could reduce that from $26.6 \%$ to $12.8 \% .^{2}$ Another potential harm from LDCT screening is radiation exposure. Evidence from several RCTs and cohort studies showed the exposure from 1 LDCT scan to be 0.65 to $2.36 \mathrm{mSv}$, whereas the annual background radiation in the United States is $2.4 \mathrm{mSv}$. The modeling studies estimated that there would be 1 death caused by LDCT for every 18.5 cancer deaths avoided. ${ }^{1,11}$

\section{WHAT'S NEW}

\section{Expanded age range, reduced pack-year history}

Annual lung cancer screening is now recommended to begin for patients at age 50 years with a 20-pack-year history instead of age 55 years with a 30-pack-year history. This would nearly double ( $87 \%$ overall) the number of people eligible for screening, and it would include more Black patients and women, who tend to smoke fewer cigarettes than their White male counterparts. The American College of Radiology estimates that the expanded screening criteria could save between 30,000 and 60,000 lives per year. ${ }^{12}$

\section{CAVEATS}

Screening criteria for upper age limit, years since smoking remain unchanged

For those patients who quit smoking, the guidelines apply only to those who have 
stopped smoking within the past 15 years. Furthermore, the benefit does not extend beyond age 80 or where other conditions reduce life expectancy. And, as noted earlier, modeling studies estimate that there would be 1 death caused by LDCT for every 18.5 cancer deaths avoided.,11

\section{CHALLENGES TO IMPLEMENTATION}

\section{Concerns about false-positives, radiation exposure may limit acceptance}

Challenges would be based mostly on the need for greater, more detailed dialogue between physicians and patients at higher risk for lung cancer in a time-constrained environment. Also, LDCT may not be available in some areas, and patients and physicians may have concerns regarding repeated CT exposure. In addition, false-positive results increase patient stress and may adversely affect both patient and physician acceptance. JFP

\section{ACKNOWLEDGEMENT}

The PURLs Surveillance System was supported in part by Grant Number UL1RR024999 from the National Center for Research Resources, a Clinical Translational Science Award to the University of Chicago. The content is solely the responsibility of the authors and does not necessarily represent the official views of the National Center for Research Resources or the National Institutes of Health.

Copyright () 2021. The Family Physicians Inquiries Network. All rights reserved.

\section{References}

1. US Preventive Services Task Force. Lung cancer: screening. Final recommendation statement. March 9, 2021. Accessed August 19, 2021.https://uspreventiveservicestaskforce.org/uspstf /recommendation/lung-cancer-screening

2. American Cancer Society. Key statistics for lung cancer. Updated January 12, 2021. Accessed August 19, 2021. www.cancer.org/ cancer/lung-cancer/about/key-statistics.html

3. National Cancer Institute. Cancer Trends Progress ReportFinancial Burden of Cancer Care. National Institutes of Health; 2015

4. National Cancer Institute. Cancer Trends Progress ReportFinancial Burden of Cancer Care. National Institutes of Health. Updated July 2021. Accessed August 19, 2021. https:// progressreport.cancer.gov/after/economic_burden

5. Alberg AJ, Brock MV, Ford JG, et al. Epidemiology of lung cancer: diagnosis and management of lung cancer, 3rd ed: American College of Chest Physicians evidence-based clinical practice guidelines. Chest. 2013;143(5 suppl):e1S-e29S. doi: 10.1378/chest.12-2345

6. Samet JM. Health benefits of smoking cessation. Clin Chest Med. 1991;12:669-679.

7. Siegel RL, Miller KD, Jemal A. Cancer statistics, 2015. CA Cancer J Clin. 2015;65:5-29. doi: 10.3322/caac.21254

8. National Lung Screening Trial Research Team; Aberle DR, Adams AM, Berg CD, et al. Reduced lung-cancer mortality with low-dose computed tomographic screening. $N$ Engl J Med. 2011;365:395-409. doi: 10.1056/NEJMoal102873

9. Pinsky PF, Church TR, Izmirlian G, et al. The National Lung Screening Trial: results stratified by demographics, smoking history, and lung cancer histology. Cancer. 2013;119:3976-3983. doi: $10.1002 /$ cncr.28326

10. de Koning HJ, van der Aalst CM, de Jong PA, et al. Reduced lungcancer mortality with volume CT screening in a randomized trial N Engl J Med. 2020;382:503-513. doi: 10.1056/NEJMoa1911793

11. Meza R, Jeon J, Toumazis I, et al. Evaluation of the Benefits and Harms of Lung Cancer Screening With Low-Dose Computed Tomography: A Collaborative Modeling Study for the U.S. Preventive Services Task Force. Agency for Healthcare Research and Quality; 2021.

12. American College of Radiology. Updated USPSTF lung can cer screening guidelines would help save lives. July 7, 2020 Accessed August 19, 2021. www.acr.org/Media-Center /ACR-News-Releases/2020/Updated-USPSTF-Lung-Cancer -Screening-Guidelines-Would-Help-Save-Lives

\section{8 MEDJOBNETWORK, com Physician $\bullet$ NP/PA Career Center}

\section{The first mobile job board for Physicians, NPs, and PAs}

\section{Mobile Job Searches - access MedJobNetwork.com on the go from your smartphone or tablet}

\section{Advanced Search Capabilities - search for jobs} by specialty, job title, geographic location, employer, and more

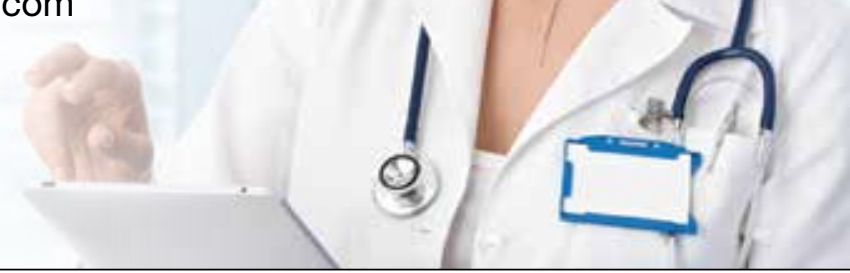

